\title{
On the use of hourly pricing in techno-economic analyses for solar photovoltaic systems is
}

\author{
Nelson Sommerfeldt*, Hatef Madani \\ KTH Royal Institute of Technology, Department of Energy Technology, Brinellvägen 68, SE-100 44 Stockholm, Sweden
}

\section{A R T I C L E I N F O}

\section{Article history:}

Available online 17 March 2015

\section{Keywords}

Solar PV

Techno-economic analysis

Dynamic prices

Time-of-use

Hourly

Typical price year

\begin{abstract}
A B S T R A C T
The use of hourly prices in distributed photovoltaic (PV) techno-economic analysis is rare, but may become necessary as time-of-day retail pricing becomes more common. A methodology is presented for selecting an hourly price curve suitable for long-term analysis, called the typical price year (TPY), which is based on the methodology for TMY weather data. Using a techno-economic analysis with annual revenues and net present value as indicators, a TPY curve for the Swedish market is validated and then compared to 18 price simplification methods to determine the error introduced by the use of non-hourly prices. Results show that the TPY method produces a curve which accurately represents long term pricing trends, but using a static annual mean introduces minor revenue errors of $1.3 \%$. This suggests the TPY may not be necessary in the Swedish market, but further analysis of the method is suggested for other markets.
\end{abstract}

(c) 2015 Elsevier Ltd. All rights reserved.

\section{Introduction}

Solar photovoltaic (PV) systems are being installed at an ever increasing rate globally, and in developed regions the fastest growing sector is distributed rooftop systems [1-3]. For building owners considering a renewable energy installation, investment analysis requires predicting future electricity prices. A common method for pricing is to assume the most recent retail electricity price and apply it to all hours of the year [4-21]. This is usually a reasonable assumption given that in many places where grid connected PV is installed, owners are given a fixed feed-in tariff (FiT), power purchase agreement (PPA) or have net metering based on a static retail price [22]. However, in the E.U. and U.S., there is interest in shifting retail customers to fluctuating hourly pricing based on wholesale electricity markets [23-27]. This could lead to increased error in existing techno-economic PV analysis methods if the variable prices deviate significantly from the mean.

While it has been discussed for decades [28,29], hourly or dynamic pricing has only recently begun retail market acceptance with the advent of smart meters, demand response programs and distributed renewable energy [30,31]. In regards to solar PV

\footnotetext{
This article is based on a four-page proceedings paper in Energy Procedia Volume 61 (2015). It has been substantially modified and extended, and has been subject to the normal peer review and revision process of the journal.

* Corresponding author. Tel.: +468 7908154 .

E-mail addresses: nelson.sommerfeldt@energy.kth.se (N. Sommerfeldt), hatef. madani@energy.kth.se (H. Madani).
}

systems, Perez et al. [32] highlighted the need to consider hourly instead of static retail prices because of solar energy's generation during higher loads and prices in the United States. This notion is not lost on utilities, and has been one factor in the rapid installation of solar PV in cooling driven climates [33]. Conversely, the relatively high amount of non-dispatchable renewable generation in the German grid has even caused negative wholesale prices, highlighting the value of generation timing $[34,35]$.

The relatively recent adjustments to PV and time-of-use (TOU) pricing policy mean few techno-economic studies have considered separate purchase and selling prices or hourly pricing. A step beyond single prices, Cucchiella et al. [36] and Colmenar-Santos et al. [20] have considered separate prices for deferred grid purchases and excess sold back to the utility, but use a static price for each. Ren et al. [37] considered tiered TOU pricing in their PV system sizing optimization model. Batman et al. [38] considered tiered TOU pricing for Turkish residential electricity costs with and without solar PV. Kwan and Kwan [39] used TOU pricing for an analysis of a college campus in Los Angeles, CA to match the owner's actual purchasing conditions.

The lack of hourly, dynamic pricing in the literature represents a gap between the future evolution of electricity markets and the current methods of assessing the economic performance of solar PV systems. At the same time, determining appropriate long-term prices for every single hour, particularly in a system with a high proportion of renewables, is a considerable burden on the modeling process. Hourly pricing also opens the door to several new 


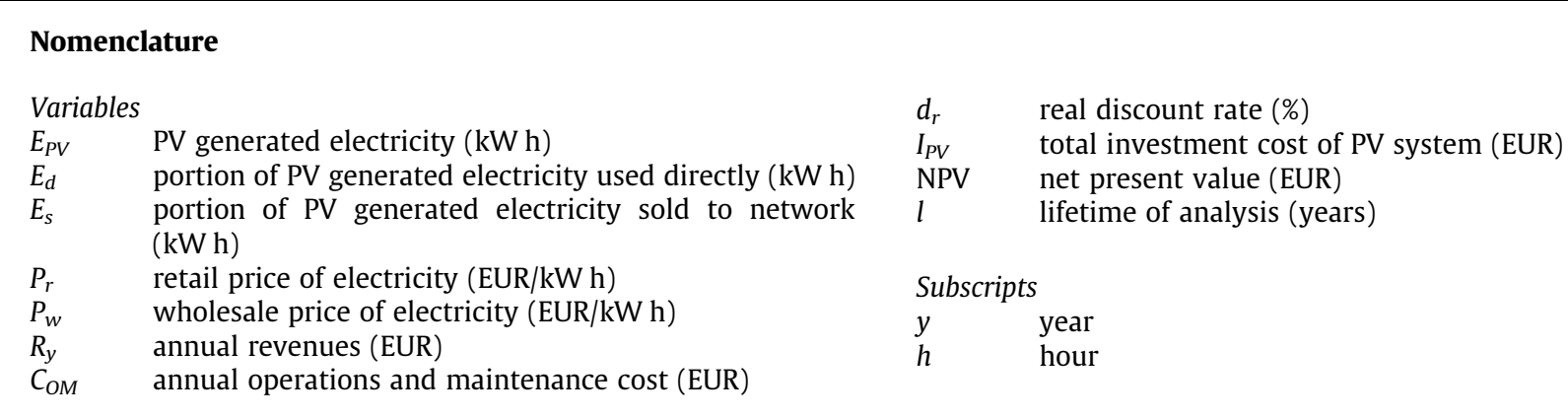

questions, such as; what are the appropriate hourly prices for longterm analysis? How can these prices be determined? Are hourly prices necessary or can a simplified price work? This study introduces a price selection methodology that creates an annual price curve for long-term analysis, called the typical price year (TPY). The objective is to assess the validity of the methodology and the sensitivity of pricing models on solar PV techno-economic analyses.

\section{Methodology}

The procedure for creating a TPY is based on an existing method used for weather data, the typical meteorological year (TMY), and is presented in detail below. The resulting price curve is used to calculate revenues of a PV installation in central Sweden, and then to calculate net present value (NPV). First year revenues and NPV are used as the basis of comparison. Test cases are based on hourly prices from the TPY as well as each calendar year between 1996 and 2013. The study can be broken into two sections; first a test of the performance of the TPY, and second, a test of simplification methods for hourly prices.

In the first test, only hourly prices are used and the results for the TPY are compared against the real prices in all other years. Next, all prices are scaled such that the mean annual price for all years is equal to 2010, the year with the highest annual mean. This test is meant to show the significance of the profile of hourly prices by removing the difference in overall scale between years. Prices are scaled to the most expensive year to avoid any negative values.

In the second test, the hourly prices are simplified across three dimensions; price source, statistical reduction methods, and pricing schemes; for a total of 18 models. Price source refers to the hourly prices used to create the static values, which come from two data sets; all prices during the time frame, and only those during PV production hours excluding the standby period. The static prices are calculated using three statistical methods; arithmetic mean, median and geometric mean. The price schemes tested include; static annual, static monthly, and a hybrid using a static annual retail rate with hourly spot selling price (currently the dominant pricing model in Sweden). A summary of the simplification models and their ID number is presented in Table 1. Hourly prices are the highest available resolution. Therefore they are assumed to be the most accurate and the basis for comparison. All years of data are tested so that a wide variety of pricing patterns and scales are considered.

All prices are inflation adjusted to 2013 SEK and converted into Euros using the 2013 average rate of 1 SEK $=0.1156$ EUR [40].

\subsection{Scope}

Sweden is the area of interest where the wholesale spot market, Nord Pool Spot (NPS), has been operating since 1996, providing 18 complete years of unregulated hourly clearing prices [41]. The volumes and timing of deferred and sold of electricity are highly dependent on the building and PV installation. This study is limited to multi-family housing, however three buildings with varying sizes and orientations are considered. Each building is tested with two PV system sizes for a total of six cases.

Inputs and assumptions made for this study are based on current Swedish PV market conditions [42], however; the focus is on the effect of the pricing models, not the actual techno-economic performance of the system. Therefore, detailed inputs (such as shading, soiling, and wiring losses) and a detailed discussion and sensitivity analysis of input assumptions are omitted.

\subsection{Building inputs and assumptions}

Electric load data with hourly resolution from actual meters is used and provided by the network utility in Linköping, Sweden [43]. It includes all electricity used in the apartments and common areas. Roof space for PV is based on the buildings where the demand data is sourced. Commonly found in Sweden, these buildings are relatively long and narrow with two/three stories and pitched roofs. The geometries do not match the metered buildings exactly and are not meant to represent a case study. A simple description of each building's geometry is reported in Table 2 and a one week sample of the demand curves is depicted in Fig. 1.

\subsection{PV system inputs and assumptions}

Typically a PV installation would be optimally sized for the best economic performance. For this study, the sizing is arbitrarily

Table 1

Summary of the price simplification models and their respective numbers.

\begin{tabular}{rlll}
\hline Number & Price source & Statistical reduction & Price scheme \\
\hline 1 & All & Mean & Annual \\
2 & All & Mean & Monthly \\
3 & All & Mean & Hybrid \\
4 & All & Median & Annual \\
5 & All & Median & Monthly \\
6 & All & Median & Hybrid \\
7 & All & Geometric mean & Annual \\
8 & All & Geometric mean & Monthly \\
9 & All & Geometric mean & Hybrid \\
10 & PV & Mean & Annual \\
11 & PV & Mean & Monthly \\
12 & PV & Mean & Hybrid \\
13 & PV & Median & Annual \\
14 & PV & Median & Monthly \\
15 & PV & Median & Hybrid \\
16 & PV & Geometric Mean & Annual \\
17 & PV & Geometric mean & Monthly \\
18 & PV & Geometric mean & Hybrid \\
\hline
\end{tabular}


Table 2

Building specific variables.

\begin{tabular}{llll}
\hline & Building 1 & Building 2 & Building 3 \\
\hline Living area $\left(\mathrm{m}^{2}\right)$ & 1500 & 3200 & 1500 \\
Annual energy use (MW h) & 34.5 & 82.1 & 55.4 \\
Roof area (m) & $6 \times 60$ & $6 \times 115$ & $6 \times 60$ \\
Roof angle (from horizontal) & $20^{\circ}$ & $20^{\circ}$ & $20^{\circ}$ \\
Roof orientation (from north) & $\mathrm{W}\left(270^{\circ}\right)$ & $\mathrm{SSW}\left(202^{\circ}\right)$ & $\mathrm{S}\left(180^{\circ}\right)$ \\
\hline
\end{tabular}

based on available roof space, covering 25\% (small) and 50\% (large) of the roof area. This is done to control for any effects economic optimization may have on the results. The only difference between system sizes is the quantity of modules and inverters. Total annual electricity demand for all buildings is assumed to remain unchanged throughout the system lifetime. The sizes of each installation are shown in Table 3 and the remaining technical inputs used across all PV scenarios and cases are shown in Table 4. Modeling of the PV systems is performed with the System Advisor Model [44].

\subsection{Economic equations, inputs, and assumptions}

Revenues are calculated as the sum of deferred retail purchases from and wholesale electricity sold to the grid, as described in Eq. (1). The quantities for $E_{d}$ are considered equal to $E_{P V}$ until $E_{P V}$ is greater than demand, in which case the excess becomes $E_{s}$. No additional metered subsidies, such as a feed-in tariff or net metering, are considered. In all cases, the difference between the retail and wholesale price is assumed to be $0.096 \mathrm{EUR} / \mathrm{kWh}$, and includes; network fee, carbon and renewable energy subsidies, energy taxes and value added tax. This is based on the most recent contracts for retail electricity consumers in Sweden [45].

$R_{y}=\sum_{h=1}^{8760}\left(E_{d} P_{r}+E_{s} P_{w}\right)_{h}$

NPV is calculated using a discounted cash flow over a lifetime $(l)$, taking into account; revenues $\left(R_{y}\right)$, installation costs $\left(I_{P V}\right)$, and operations and maintenance costs $\left(C_{O M}\right)$ as shown in Eq. (2). No debt or income tax costs are considered. For each case, the first year's prices are taken directly from the test year or TPY and adjusted for inflation. The prices for subsequent years use the same curve (i.e. results for 1996 only use prices from 1996, not 1996, $1997,1998 .$. ) and grow at a fixed rate. The rate of increase is even across the entire year; i.e. the shape of the price curve does not change and is only translated up a fixed percentage each year. The economic inputs related to NPV are listed in Table 5.

$\mathrm{NPV}=\sum_{y=1}^{l} \frac{\left(R_{y}-C_{O M}\right)}{\left(1+d_{r}\right)^{y}}-I_{P V}$

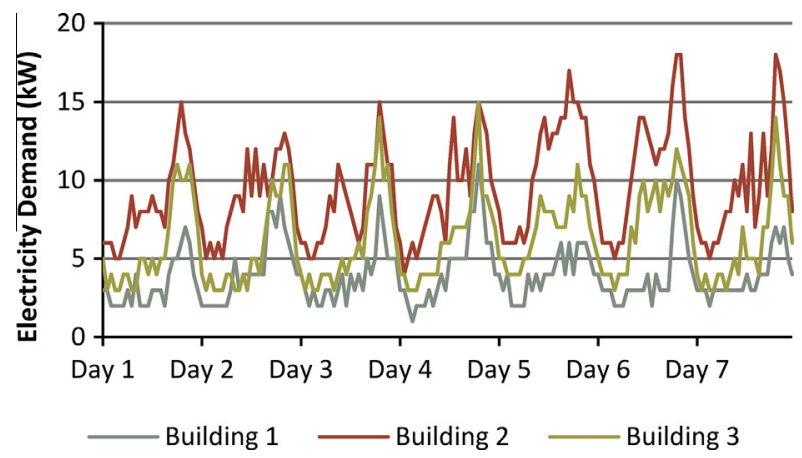

Fig. 1. One week of electric load data in $\mathrm{kW}$ for each test building.
Table 3

PV installation sizes for all buildings $\left(\mathrm{kW}_{\mathrm{p}}\right)$.

\begin{tabular}{llll} 
& Building 1 & Building 2 & Building 3 \\
\hline Small (25\%) & 10.8 & 21.6 & 10.8 \\
Large (50\%) & 21.6 & 43.2 & 21.6
\end{tabular}

Table 4

Technical assumptions for a typical PV system in Sweden.

\begin{tabular}{ll}
\hline Weather data & TMY2 for Stockholm/Arlanda \\
Modules & Trina solar TSM-240PA05 \\
Inverters & SMA SB10000TL \\
Annual PV degradation & $0.5 \%$ \\
Electricity demand escalation rate & $0 \%$ \\
\hline
\end{tabular}

Table 5

Economic assumptions for a typical PV system in Sweden.

\begin{tabular}{ll} 
Installed cost & $1.5 \mathrm{EUR} / \mathrm{W}_{\mathrm{pDC}}$ \\
Annual O\&M cost & $0.23 \mathrm{EUR} / \mathrm{kW}_{\mathrm{p}}-\mathrm{y}$ \\
Real discount rate $\left(d_{r}\right)$ & $6 \%$ \\
Real annual price escalation rate & $2 \%$ \\
Lifetime $(l)$ & 30 years \\
\hline
\end{tabular}

\section{Procedure to create a typical price year}

Wholesale electricity prices in Sweden are largely driven by the deregulated spot market, Nord Pool Spot [41]. The real spot prices between 1996 and 2013 are graphed on separate plots in Fig. 2 for comparison. Sweden was divided into four bidding zones in November of 2011. In an attempt to create a process for the whole of Sweden, the zone prices have been averaged back together.

One notable characteristic of the price curves is that they have been volatile with no discernible annual pattern. While approximately half of the years have mostly flat curves with slightly lower summertime prices, the others have distinctly unique profiles. These features make it difficult to discern exactly what constitutes a typical price year. The Nordic electricity system has relatively high amounts of hydropower and electric heating. This makes the system particularly sensitive to weather, where dry and/or cold winters can lead to a lack of supply and/or excessive demand [46].

\subsection{Methodological foundation}

The semi-predictable but inconstant behavior of the spot market is somewhat similar to annual weather patterns, inspiring the methodology for creating a TPY to be borrowed from meteorology. In the creation of a TMY data set, which are commonly used for many long range energy simulations, specific months of data are chosen based on how representative they are of the most probabilistic month, and then concatenated to create the annual weather data [47].

A strength of the TMY methodology is that the raw data is not manipulated, but instead selected as being the most representative of the greater data pool [48]. This means that natural transitions and randomly occurring spikes or dips are still present, whereas using mean or median values would neutralize them.

To apply this technique to electricity prices, each hour of the day for all days within a given month is considered its own data set. First, a statistical analysis (types of analyses are discussed in detail in the next section) is performed to determine the most representative, or typical, value for each value of the month across all years. The typical value is then compared to the actual values to calculate a normalized root mean square (NRMS) for all $24 \mathrm{~h}$ for 
1996



1999

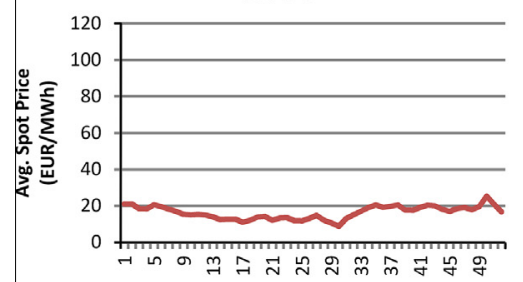

2002

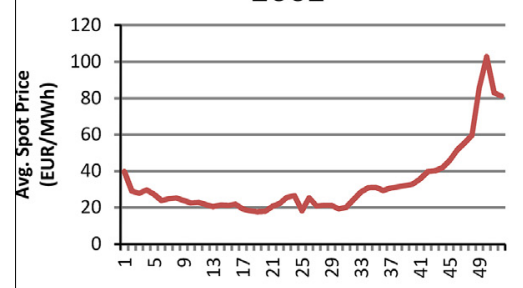

2005

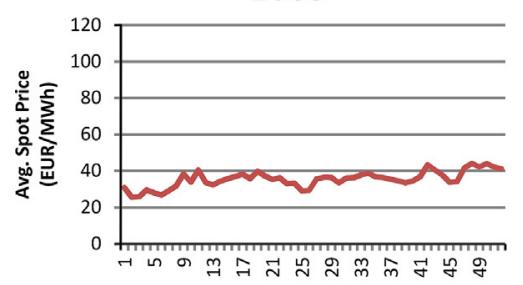

2008

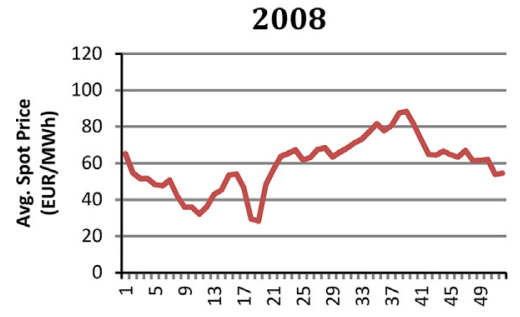

2011

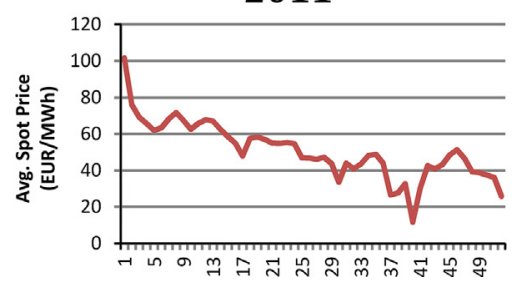

1997

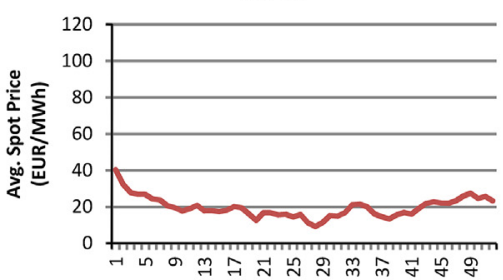

2000

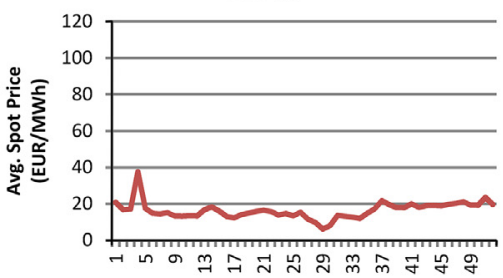

2003

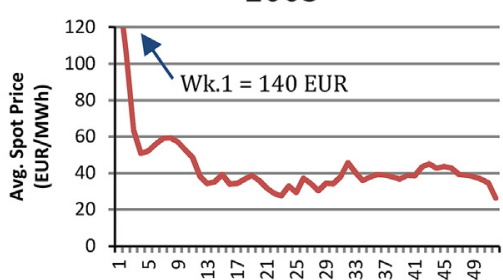

2006

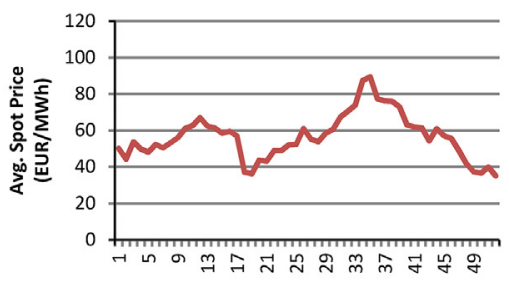

2009



2012

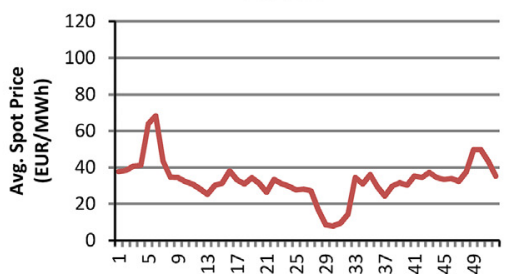

1998



2001

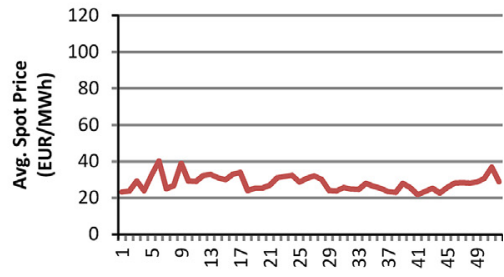

2004

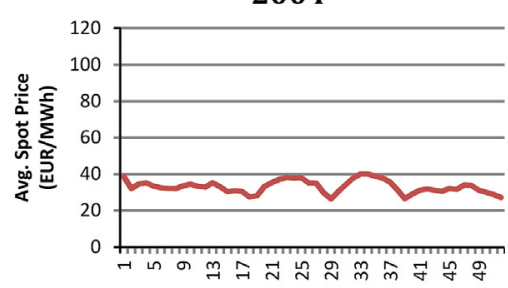

2007



2010

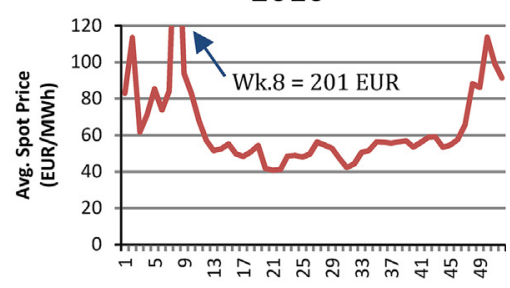

2013



Fig. 2. Weekly average spot prices in EUR/MW h for Sweden since joining Nord Pool Spot. 
Step 1: Using each year of data for a given month, compute the "typical" price for each hour of the day.
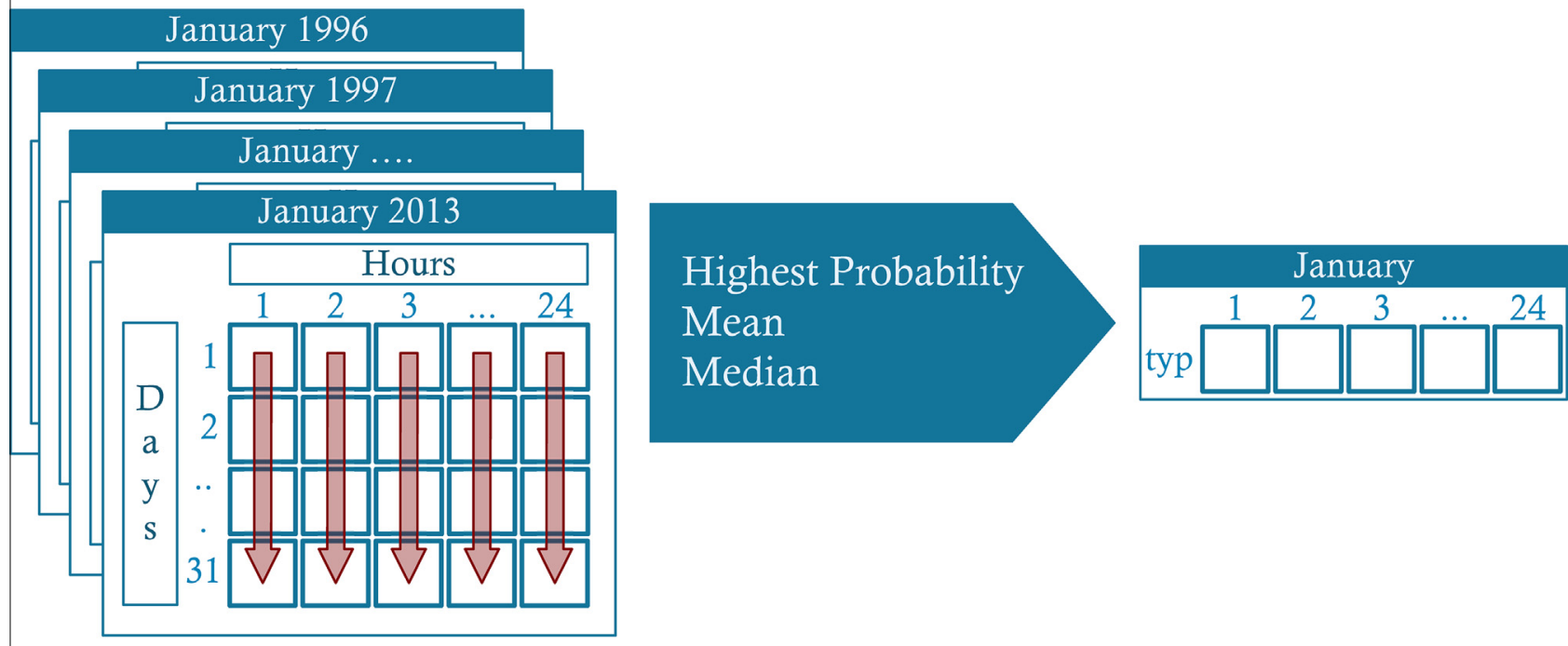

Step 2: Use the typical day to compare to all days in a given month. Calculate the NRMS for each hour.

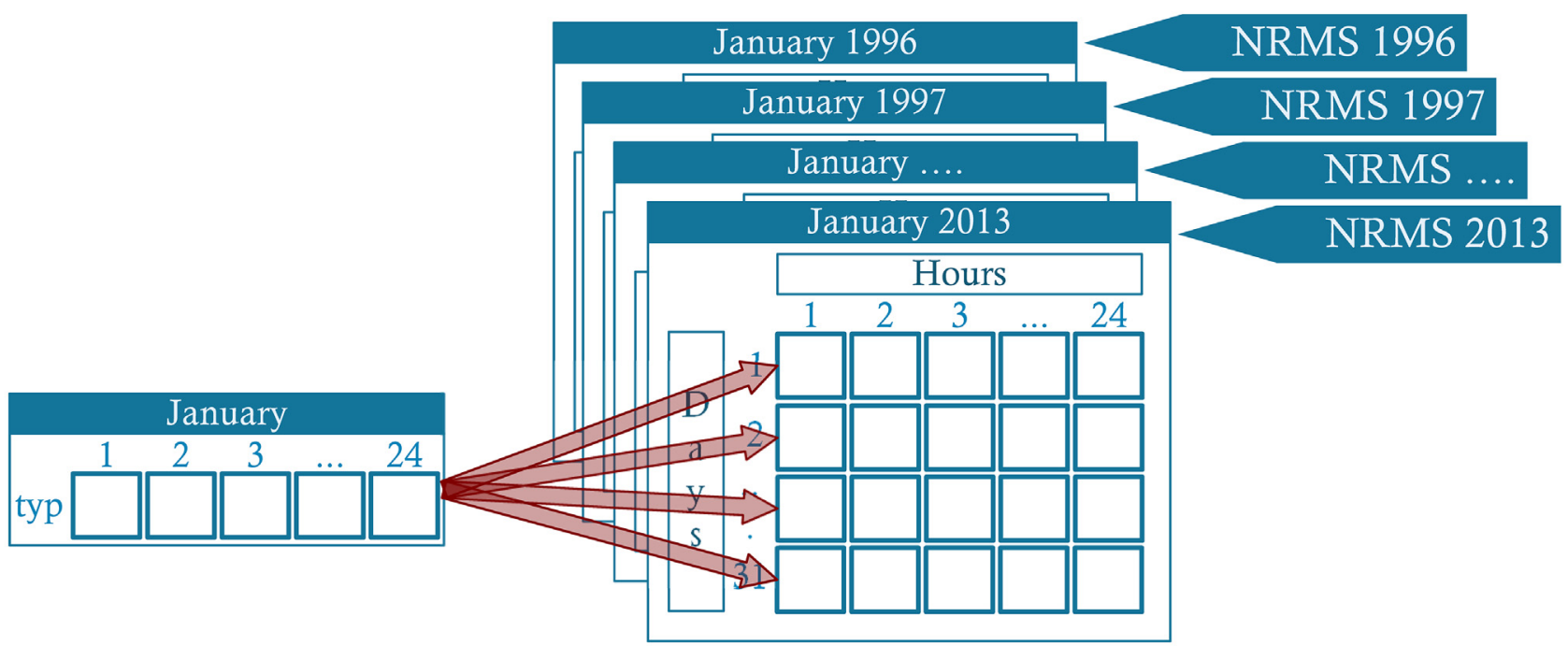

Step 3: Select years with the lowest average NRMS for each month to build a year of original (real) prices.
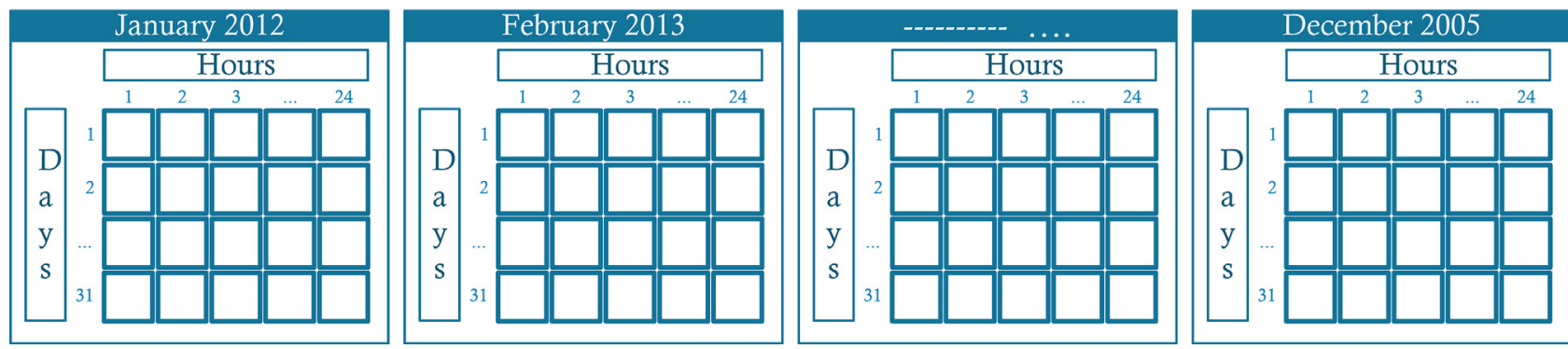

Fig. 3. Graphical representation of the process to create a typical price year (TPY).

each year. The hourly NRMS values are averaged together and for each month, the year that has lowest NRMS is chosen as being the most representative. The (real) hourly pricing data for that month is then used to concatenate the final typical year curve. This process is represented graphically in Fig. 3.

The final step, which is not present in the TMY method, is to calibrate the TPY data such that the average annual price matches the average price of the most recent year of data. This is done so that the magnitude of the curve is relevant to the current market prices. Calibration is done by simply translating the entire TPY curve by the difference of its mean with the most recent year. For the testing in this study, this step has been omitted in order to compare the raw data selected by the process to the years which the data is selected. However; this is done only for testing and in a 

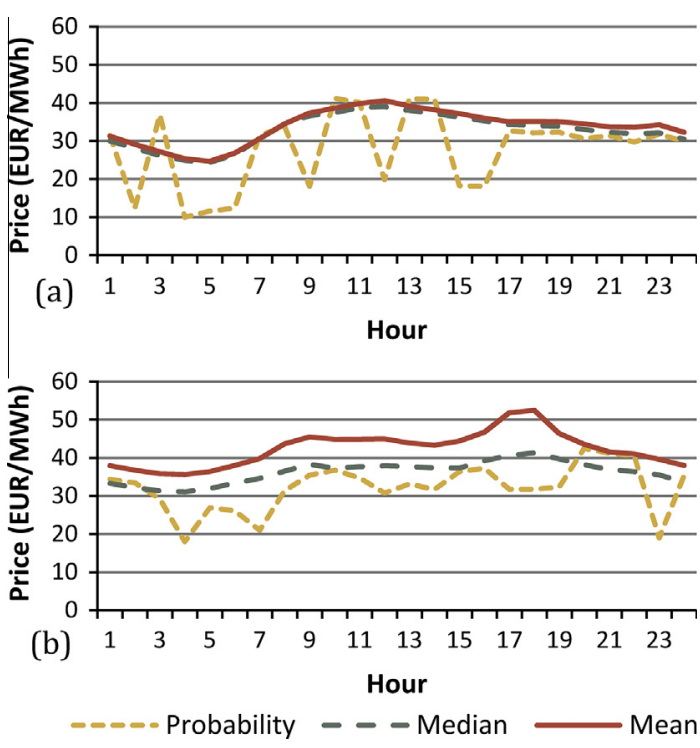

Fig. 4. Daily spot price curves for the most representative June (a) and December (b) days, in EUR/MW h.

situation where the TPY was to be used for a techno-economic analysis, it would be expected to scale the curve accordingly.

\subsection{Statistical analysis for selecting months}

The selection criterion for the most representative prices for a given month is a critical feature of the method, therefore several alternatives have been reviewed; highest probability, mean and median.

Examples of typical diurnal prices for June (a) and December (b) determined with each statistical process are shown in Fig. 4. It can be seen that the mean and median curves are smooth and track each other closely, while the highest probability curves are relatively unstable.

Although similar, the differences between the mean and median curves vary by month. In the summer they are closer, for example in June being between $0.0 \%$ and $6.3 \%$. In December the differences are between $9.2 \%$ and $21.4 \%$. The larger difference in
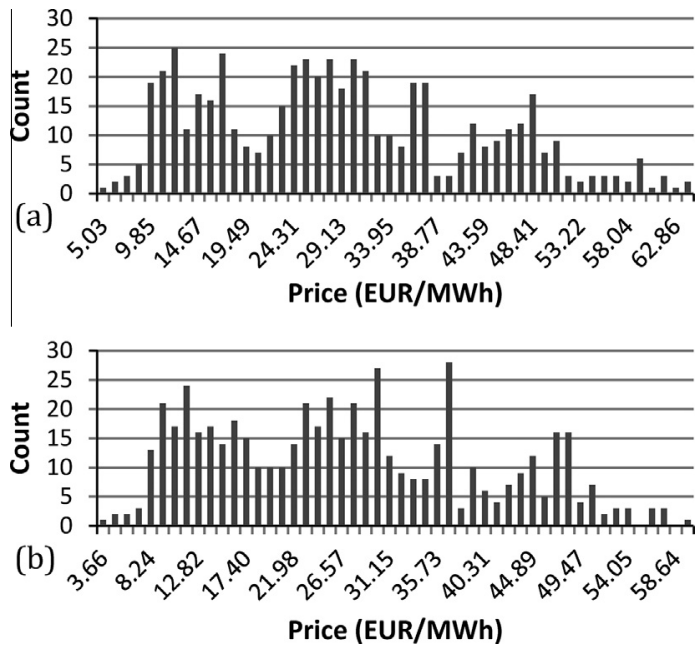

Fig. 5. Histograms showing the distribution of prices in EUR/MW h during hours two (a) and three (b) in June.
Table 6

Year and corresponding NRMS for each selection criteria alternative.

\begin{tabular}{|c|c|c|c|c|c|c|}
\hline \multirow[t]{2}{*}{ Month } & \multicolumn{2}{|c|}{ Probability } & \multicolumn{2}{|l|}{ Mean } & \multicolumn{2}{|l|}{ Median } \\
\hline & $\begin{array}{l}\text { Selected } \\
\text { year }\end{array}$ & NRMS & $\begin{array}{l}\text { Selected } \\
\text { year }\end{array}$ & NRMS & $\begin{array}{l}\text { Selected } \\
\text { year }\end{array}$ & NRMS \\
\hline January & 1998 & 30.90 & 2012 & 59.02 & 2004 & 24.40 \\
\hline February & 2002 & 26.15 & 2013 & 30.78 & 2004 & 26.21 \\
\hline March & 1996 & 21.00 & 2004 & 29.53 & 1996 & 18.58 \\
\hline April & 1997 & 60.76 & 2005 & 30.61 & 2001 & 28.94 \\
\hline May & 1996 & 85.30 & 2004 & 52.95 & 1996 & 51.88 \\
\hline June & 2001 & 73.05 & 2004 & 42.88 & 2001 & 40.11 \\
\hline July & 2001 & 104.40 & 2013 & 40.35 & 2013 & 40.83 \\
\hline August & 2004 & 23.32 & 2005 & 26.81 & 2005 & 25.98 \\
\hline September & 2003 & 34.00 & 2003 & 26.83 & 2005 & 26.64 \\
\hline October & 1996 & 38.62 & 2002 & 35.75 & 1996 & 35.38 \\
\hline November & 2004 & 44.50 & 2003 & 33.99 & 2012 & 38.96 \\
\hline December & 1996 & 47.16 & 2005 & 42.84 & 1996 & 39.69 \\
\hline
\end{tabular}

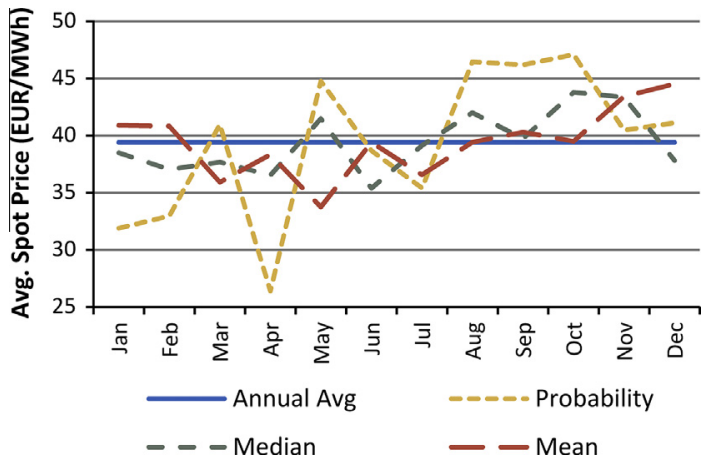

Fig. 6. Average monthly price in EUR/MW h for each method.

winter is due to the increase in volatility, where high price spikes are more common.

The instability in the probability results can be traced to the distribution pattern. For example, in hours two and three in June, the most probable prices are 12.26 EUR/MW h and 36.87 EUR/MW h, respectively. However, reviewing the histograms in Fig. 5 shows that the price distributions during those two hours are actually quite similar (note the slightly different bin values on the $x$-axis). The prices are widely spread out with multiple peaks, rather than the single peak of normal distribution, which results in the unstable price curves seen in Fig. 4 .

NRMS and selected year results from each statistical analysis are shown in Table 6. Fig. 6 shows the resulting monthly averages from each TPY method, 2013 and average annual price for 2013. The instability of the probability technique's results excludes it from use in the TPY methodology. For the mean and median methods, while the selected months differ for most years, the NRMS values are usually within 2-3 EUR/MW h, with January and March as

Table 7

PV production results for each installation scenario.

\begin{tabular}{lrll}
\hline \multicolumn{5}{c}{ PV generation (MW h/yr) } & Solar fraction (\%) & Internal use (\%) \\
\hline $\begin{array}{l}\text { Building } \\
\text { Small }\end{array}$ & 8.6 & & \\
Large & 17.2 & 24.9 & 77.6 \\
Building 2 & & 49.9 & 51.9 \\
Small & 20.6 & & \\
Large & 41.2 & 25.1 & 83.1 \\
Building & & 50.3 & 56.3 \\
Small & 10.4 & & \\
Large & 20.8 & 18.8 & 91.7 \\
\hline
\end{tabular}



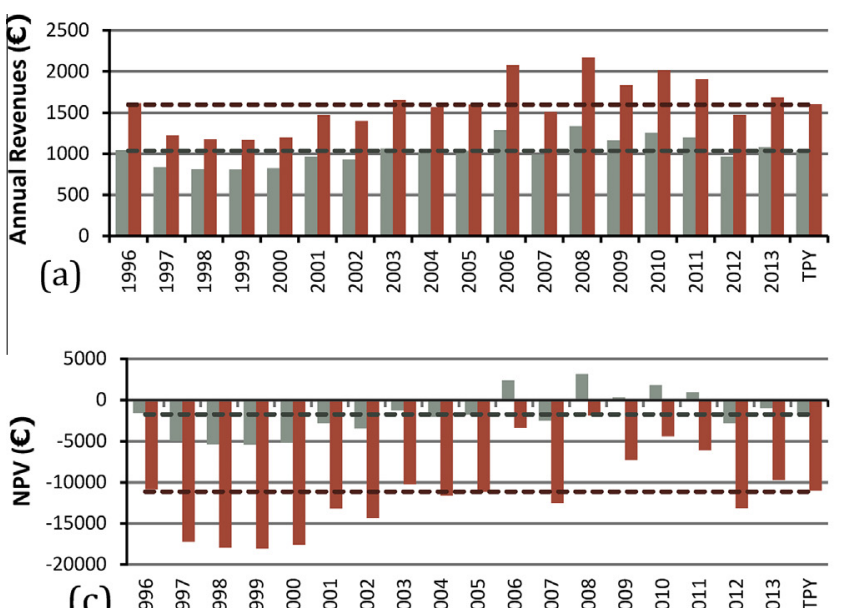


Small Large ------S Small Mean ------ Large Mean

Fig. 7. First year revenues ( $a$ and b) and NPV (c and d) in EUR for the real (a and c) and scaled (b and d) prices for building 1.

outliers. The resulting TPY curves in Fig. 6 have all been translated to have the same annual average shown in the chart.

To select a method, one option would be to use the lower average annual NRMS, which favors the median technique (33.1) over the mean (37.7). However, for this data set the median method resulted in above average prices in May and below average prices in December, which is rare for any given year. The monthly averages generated by the mean method does not have this feature, therefore its pricing values are used for this study.

\section{Results}

The results of the tests are presented in three sections; the technical performance of the PV systems, the first test comparing the performance of the TPY method, and the second test comparing price simplification techniques to hourly data.

\subsection{PV system performance}

PV simulation results are shown in Table 7, describing the annual generation, and percent of PV generation as compared to total demand and amount used within the building (versus sold to the grid). Buildings 1 and 2 have similar solar fractions, which are higher than building 3; however building 3 has the highest internal fraction, or amount of PV electricity being used internally. The solar fractions are reasonable for PV installations in Sweden.

\subsection{Test 1: TPY performance}

The first year revenue and NPV results for both installation sizes for building 1 are shown in Fig. 7a-d. Each chart shows the original values as well as the mean across all years.

Fig. 7a and c shows the results for the unmodified real prices, where it can be seen that the TPY results are very close to the mean across all years. For revenues, the TPY is only $0.4 \%$ from the mean and $1.1 \%$ different from the median in the small installation, and the results are marginally higher for the large. It should be noted that differences for NPV as a percentage are highly sensitive to the values proximity zero, making comparisons across cases difficult. Direct comparison of NPV values can be made in the figures where it can be seen that TPY results are also close to the mean in each case.
When comparing the real to the adjusted values, it can be seen in the revenues (Fig. 7a and b) that the adjusted prices have a much less variation between years. The standard deviation of the real prices across years is $€ 159$, whereas in the adjusted prices it is only $€ 35$, a reduction of $78 \%$. A similar difference is seen in the $50 \%$ installation. The reduction in standard deviation in the NPV results is similar in both installations as well. This suggests that revenues and NPV are more sensitive to predictions of future price growth rather than specific hourly price patterns. It can also be seen that the TPY is within $1 \%$ of the mean value of these revenue and NPV results as well, indicating again that it has a reasonably neutral profile suitable for long-term analysis.

While the absolute values for each building vary, the results for buildings 2 and 3 display similar trends as building 1. The TPY in both buildings is within $1 \%$ of the mean in all revenue cases and the variation in the adjusted prices is about $80 \%$ less than the real prices.

\subsection{Test 2: price simplification}

In the second test, the 18 price simplification models (described under the Methodology section and Table 1) are used in the same economic analysis as hourly prices and compared. Because it is difficult to view all of the results, only the hourly base case and simplified models with the least and most deviation with respect to the base case are reported.

Fig. 8 reports the economic indicators for building 1 . Focusing on the revenues for building 1, in Fig. $8 \mathrm{a}$ and $\mathrm{b}$ it can be seen that the difference between the hourly and simplified models are usually very low. The highest possible spread in results came from the 2010 prices, where the choice of simplification model could result in a $4.5 \%$ higher or $5.6 \%$ lower annual revenue. The TPY had low differences in all variants, with the best being no. 14 at $-0.2 \%$ and the worst no. 8 at $-2.1 \%$.

The results for NPV, shown in Fig. $8 \mathrm{c}$ and d, are similar in that most years have a good match. Similarly small errors are shown in the TPY results. However, in some years the differences are large enough to potentially affect an investment decision. ${ }^{1}$ For example, returning to 2010, the hourly NPV result for the small installation is

\footnotetext{
${ }^{1} \mathrm{NPV}$ is intended to make a yes/no decision on investment based on a positive/ negative result.
} 

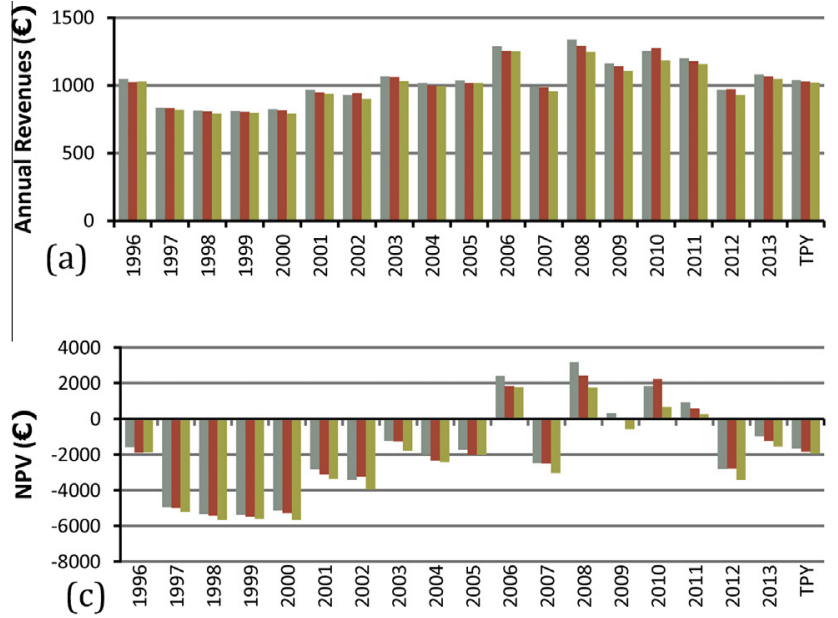
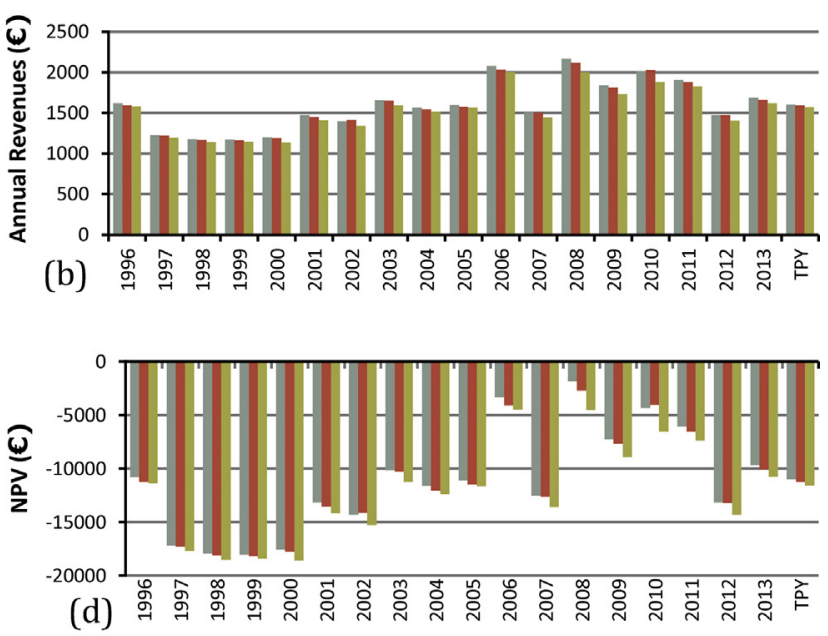

- Hourly $\quad$ Least Deviation Most Deviation

Fig. 8. First year revenues ( $a$ and b) and NPV ( $c$ and d) in EUR for the small (a and c) and large (b and d) PV installations in building 1.

$€ 1820$ and the result from no. 1 is $€ 2733$ resulting in profitability indices $^{2}$ of $11.2 \%$ and $16.9 \%$, respectively. This difference could potentially affect an investor considering multiple PV systems or other options such as building efficiency. It is also possible for the NPV to reverse signs, reversing the decision to invest, as it is in 2009 (Fig. 8c).

The results from building 2 (not shown) have similar revenue difference values to building 1 , however the model with the least deviation in the small installation is no. 11 (instead of no. 12) and the most is no. 7 (instead of no. 8). The NPV of both systems have several years which are close to zero, meaning the results have an increased sensitivity to the simplification model. This sensitivity may have an impact on the final investment decision depending on hourly pricing patterns.

The most and least deviating models for building 3 are no. 12 and no. 7, respectively (not shown), similar to the other two buildings. The revenue and NPV results also have very similar differences between models, with no remarkable differences.

To capture the overall accuracy of each simplification model, the root mean square (RMS) is calculated using the difference between the hourly and model results from each year, installation size and economic indicator (revenues and NPV). The results are then summed together and shown in Fig. 9. The purpose is not to determine the absolute accuracy, but instead show the relative accuracy of each simplification model.

From the RMS sums, general rules about each price simplification model can be made;

- The hybrid model is more accurate than the static monthly model, which is usually more accurate than the static annual values.

- An arithmetic mean is more accurate than median or geometric mean.

- Sourcing prices from hours with PV production is more accurate than using prices from every hour of the year.

Focusing on the best performing cluster, no. 10-12 (PV/Mean), the performance of the annual static value (no. 10) is nearly equal to the monthly (no. 11) and only slightly worse than the hybrid (no. 12). It can also be seen that method no. 1 (All/Mean), which

\footnotetext{
2 In this paper, profitability index is defined as [NPV/Initial investment], and is used to compare the performance of multiple exclusive options.
}

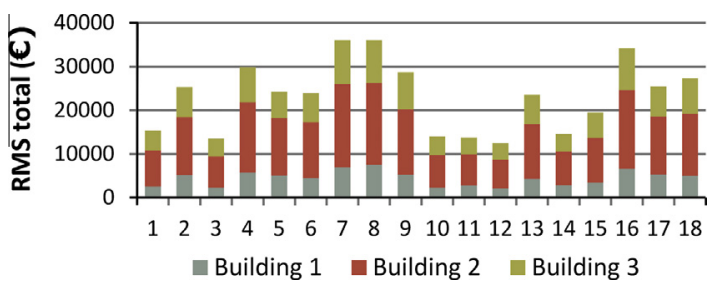

Fig. 9. Root mean square (RMS) totals for the simplification variants compared to the hourly values for each building.

is currently used by most studies, has an RMS value which is also amongst the highest performing models.

\section{Discussion}

Noted and discussed in the test 1 results, the TPY produces economic indicators which are in line with the mean values across all years. This may seem intuitive given that the TPY is created from a collection of values which are meant to represent this data set. However, the method does not directly seek mean values, but seeks out raw values concatenated to represent a year. Therefore, it is notable that the TPY provides a good correlation with the mean and is a positive indication of its suitability for long-term investment analysis.

Using a static, annual mean value is the pricing method used in most techno-economic analysis. In the prices shown here, this results in revenues which are within only a few percent of the hourly values. There are pricing patterns from some years which introduce much higher error values up to $7.3 \%$, however these are limited to only a few years and do not represent the long-term market. Using a mean annual price compared to the hourly TPY prices, which represents the long-term market, has errors of less than two percent. Given the additional effort in acquiring and selecting hourly prices and building loads, this uncertainty is likely to be considered acceptable, especially in the context of other assumptions in the analysis, such as prices changes over time which have been shown in test 1 to be a greater source of error than hourly pricing patterns.

The focus on hourly profiles highlights the highly specific nature of this study to the Nord Pool Spot market. Other markets with different generation portfolios, demand profiles, and climates can 
have very different pricing patterns which could lead to different results. The output of the PV and building load curves can also alter results even within a single market. This is exemplified in the high errors caused by price simplification in NPV results from some of the years. The focus of this study is on typical multi-family houses in Sweden, and an attempt has been made to examine different buildings in which hourly data is available. The consistency of results between the buildings suggests a good performance of the model. However, other building types, such as single family houses or commercial buildings, and other regions are suggested for future studies to widen the applicable scope of the TPY method.

A critical limitation to the TPY method is the unpredictable nature of prices. Prices are free to move completely independent of past patterns based on a wide variety of inputs, many from human interaction. Considering the TMY method, weather can be reasonably expected to be similar each year, even considering climate change. The TPY method does not consider the underlying cause of price formation; it simply tracks patterns and assumes the generation portfolio and electricity demand under which the prices formed remain constant over time. This is the case for this study, but may not be true in the future or in other markets. The energy systems of many nations are under careful scrutiny, and there is the potential for dramatic changes, therefore previous price formations may not represent future patterns. ${ }^{3}$

\section{Conclusions}

The use of hourly prices in photovoltaic (PV) techno-economic analysis is rare, but may become more relevant as dynamic pricing becomes more common and distributed PV is integrated more closely with the spot market. This study proposes a methodology to create a typical price year (TPY) for use with hourly prices and explores the effects pricing models have on the economic analysis of PV systems.

The results show that the TPY produces revenue and NPV values which are very close to the mean value of all of the years used to create it. Given that the TPY is a concatenation of raw price values, this is a positive indication that the method is producing a price curve which is representative of a long-term pattern. When testing the accuracy of 18 price simplification models against hourly prices, the best performing model used a static annual purchase price with hourly sales prices. Using a static annual average for purchases and sales introduces a maximum error in annual revenues of $7.3 \%$, and less than $1.5 \%$ for the TPY.

The conclusions from the observations in this study are as follows;

- The typical price year produces a neutral, hourly price curve suitable for long-term techno-economic PV analysis.

- Using a static annual price rather than hourly prices introduces acceptably small errors considering long-term pricing.

- A static annual price can cause much higher errors in specific years but do not have an effect on the results of the long-term investment analysis.

- The typical price year is not predictive of future energy systems or the price developments where significant changes in the energy system are expected.

The conclusions presented here are based on prices and scenarios unique to the Swedish market, and provide insight into the use of hourly prices for researchers and analysts in Sweden. While the

\footnotetext{
${ }^{3}$ In an energy system with $100 \%$ renewables, where output would be entirely linked to weather, this backward/forward prediction could be more relevant. However this still only applies to supply and prices are still subject to demand and elasticity.
}

results on price simplification are difficult to generalize for other regions, the TPY method can be applied to any market with sufficient data. It is possible hourly pricing will have a more significant effect on investment outcomes in other climates, electricity markets, building types or technologies. Therefore, additional testing of the TPY method is needed to determine the impact on a broader scale.

\section{Acknowledgements}

This research is funded by The Swedish Research Council Formas (no. 2012-256). The authors would also like to thank Nord Pool Spot for supplying market price data, and Tekniska Verket and BRF Gasellen for supplying electricity demand data. Further thanks to T. af Klintberg, H. Muyingo and B. Palm for their input during model development.

\section{References}

[1] IEA. World energy outlook. Paris; 2013.

[2] REN21. Renewables 2014 global status report. Paris; 2014

[3] IEA PVPS. Trends 2013 in photovoltaic applications. Paris; 2013.

[4] Chabot B. From costs to prices: economic analysis of photovoltaic energy and services. Prog Photovoltaics Res Appl 1998;6:55-68.

[5] Lesourd J-B. Solar photovoltaic systems: the economics of a renewable energy resource. Environ Model Softw 2001;16:147-56.

[6] Spanos I, Duckers L. Expected cost benefits of building-integrated PVs in UK, through a quantitative economic analysis of PVs in connection with buildings, focused on UK and Greece. Renew Energy 2004:29:1289-303.

[7] Bernal-Agustín JL, Dufo-López R. Economical and environmental analysis of grid connected photovoltaic systems in Spain. Renew Energy 2006:31:1107-28.

[8] Celik AN. Present status of photovoltaic energy in Turkey and life cycle technoeconomic analysis of a grid-connected photovoltaic-house. Renew Sustain Energy Rev 2006;10:370-87.

[9] Bazen EF, Brown MA. Feasibility of solar technology (photovoltaic) adoption: case study on Tennessee's poultry industry. Renew Energy 2009;34:748-54.

[10] Poullikkas A. Parametric cost-benefit analysis for the installation of photovoltaic parks in the island of Cyprus. Energy Policy 2009;37:3673-80.

[11] Al-Salaymeh A, Al-Hamamre Z, Sharaf F, Abdelkader MR. Technical and economical assessment of the utilization of photovoltaic systems in residential buildings: the case of Jordan. Energy Convers Manage 2010;51:1719-26.

[12] Audenaert A, De Boeck L, De Cleyn S, Lizin S, Adam J-F. An economic evaluation of photovoltaic grid connected systems (PVGCS) in Flanders for companies: a generic model. Renew Energy 2010;35:2674-82.

[13] Dusonchet L, Telaretti E. Economic analysis of different supporting policies for the production of electrical energy by solar photovoltaics in western European Union countries. Energy Policy 2010;38:3297-308.

[14] Talavera DL, Nofuentes G, Aguilera J. The internal rate of return of photovoltaic grid-connected systems: a comprehensive sensitivity analysis. Renew Energy 2010;35:101-11.

[15] Harder E, Gibson JM. The costs and benefits of large-scale solar photovoltaic power production in Abu Dhabi, United Arab Emirates. Renew Energy 2011;36:789-96.

[16] Peters M, Schmidt TS, Wiederkehr D, Schneider M. Shedding light on solar technologies-a techno-economic assessment and its policy implications. Energy Policy 2011;39:6422-39.

[17] Talavera DL, Muñoz-Cerón E, de la Casa J, Ortega MJ, Almonacid G. Energy and economic analysis for large-scale integration of small photovoltaic systems in buildings: the case of a public location in Southern Spain. Renew Sustain Energy Rev 2011;15:4310-9.

[18] Ramadhan M, Naseeb A. The cost benefit analysis of implementing photovoltaic solar system in the state of Kuwait. Renew Energy 2011;36:1272-6.

[19] Mitscher M, Rüther R. Economic performance and policies for grid-connected residential solar photovoltaic systems in Brazil. Energy Policy 2012:49:688-94.

[20] Colmenar-Santos A, Campíñez-Romero S, Pérez-Molina C, Castro-Gil M. Profitability analysis of grid-connected photovoltaic facilities for household electricity self-sufficiency. Energy Policy 2012;51:749-64.

[21] Reichelstein S, Yorston M. The prospects for cost competitive solar PV power Energy Policy 2013;55:117-27.

[22] Avril S, Mansilla C, Busson M, Lemaire T. Photovoltaic energy policy: financial estimation and performance comparison of the public support in five representative countries. Energy policy 2012;51:244-58.

[23] European Council. European council conclusions for 22 May 2013; 2013.

[24] European Commission. State aid: commission adopts new rules on public support for environmental protection and energy; 2014.

[25] North Carolina State University. Database of state incentives for renewables and efficiency (DSIRE); 2014. 
[26] Prah P. States brace for utilities, solar advocates clash; 2014

[27] Glick D, Lehrman M, Smith O. Rate design for the distribution edge. Boulder, CO; 2014

[28] Boiteux M. Peak-load pricing [Translated by H.W. Izzard]. J Bus 1960;33:157-9.

[29] Kahn AE. The economics of regulation: principles and institutions. New York: John Wiley \& Sons, Inc.; 1970

[30] Joskow PL, Wolfram CD. Dynamic pricing of electricity. Am Econ Rev 2012;102:381-5.

[31] Dütschke E, Paetz A-G. Dynamic electricity pricing-which programs do consumers prefer? Energy Policy 2013;59:226-34.

[32] Perez R, Burtis L, Hoff T, Swanson S, Herig C. Quantifying residential PV economics in the US-payback vs cash flow determination of fair energy value. Sol Energy 2004;77:363-6.

[33] ClimateWire. Can solar challenge natural gas? Sci Am; 2013.

[34] Hirth L. The market value of variable renewables. Energy Econ 2013;38:218-36.

[35] Morris C. German power prices negative over weekend. Energy Transit 2014

[36] Cucchiella F, D’Adamo I, Gastaldi M, Koh SCL, Renewable energy options for buildings: performance evaluations of integrated photovoltaic systems. Energy Build 2012;55:208-17.
[37] Ren H, Gao W, Ruan Y. Economic optimization and sensitivity analysis of photovoltaic system in residential buildings. Renew Energy 2009;34:883-9.

[38] Batman A, Bagriyanik FG, Aygen ZE, Gül Ö, Bagriyanik M. A feasibility study of grid-connected photovoltaic systems in Istanbul, Turkey. Renew Sustain Energy Rev 2012;16:5678-86.

[39] Kwan CL, Kwan TJ. The financials of constructing a solar PV for net-zero energy operations on college campuses. Util Policy 2011;19:226-34.

[40] European Central Bank. ECB: euro exchange rates; 2014.

[41] Nord Pool Spot. <http://www.nordpoolspot.com/>; 2014.

[42] Lindahl J. National survey report of PV power applications in Sweden 2013. Paris; 2013.

[43] Tekniska Verken. <http://www.tekniskaverken.se/>; 2014.

[44] National Renewable Energy Laboratory. System advisor model; 2014.

[45] Statistics Sweden. Energy prices on natural gas and electricity; 2014.

[46] Swede Energy. The electricity year 2012. Stockholm; 2013.

[47] Hall I, Prairie R, Anderson H, Boes E. Generation of a typical meterological year. Annu. Meet. Am. Sect. ISES, Denver; 1978. p. 669.

[48] Crawley DB. Which weather data should you use for energy simulations of commercial buildings? ASHRAE 1998 Trans 1998;104:1-18. 